\title{
UNA SÍNTESIS DEL REGLAMENTO 650/2012: RESIDENCIA HABITUAL DEL DE CUIUS, FUNCIONES JUDICIALES, PROFESSIO IURIS. COMENTARIO A LA SENTENCIA DEL TRIBUNAL DE JUSTICIA (SALA PRIMERA) DE 16 DE JULIO DE 2020, ASUNTO C-80/19.
}

\author{
THE REGULATION 650/2012 IN A NUTSHELL: HABITUAL \\ RESIDENCE OF THE DECEASED, EXERCISE OF JUDICIAL \\ FUNCTIONS, PROFESSIO IURIS: PURPOSE TO THE CJEU \\ JUDGEMENT OF 16TH JULY 2020, C-80/19.
}

\author{
Luis F. Carrillo Pozo \\ Profesor de Derecho internacional privado \\ Universidad de Almería \\ ORCID ID: 0000-0002-5507-167X \\ Recibido:15.11.2020 / Aceptado: 11.12.2020 \\ DOI: https://doi.org/10.20318/cdt.2021.5987
}

\begin{abstract}
Resumen: La sentencia de 16 de julio de 2020 responde a una amplia gama de cuestiones, desde los fundamentos mismos sobre los que se basa la aplicación del Reglamento 650/2012 (residencia habitual, carácter internacional de la sucesión) hasta las condiciones en las que se puede hablar de elección de tribunal y de la ley reguladora de la sucesión, pasando por el transcendental concepto de tribunal. En realidad, esta sentencia no pasará a la historia (o se limita a recoger la doctrina de pronunciamientos anteriores, o se limita a dejarlo todo en manos de los tribunales nacionales, o ambas cosas a la vez), pero tiene la virtud de servir de síntesis de las aportaciones previas.
\end{abstract}

Palabras clave: sucesión con repercusión internacional, residencia habitual, tribunal, notarios, jurisdicción, Professio iuris.

Abstract: The 16 July 2020 judgment answers a wide range of queries, from the very grounds on which the application of Regulation 650/2012 is based (habitual residence, international nature of the succession) to the conditions under which a choice of court and the law governing the succession can be discussed, through the transcendental concept of court. In fact, this ruling will not go down in history (either it simply reflects the doctrine of previous decisions, or it merely leaves everything to the national courts, or both together), but it has the virtue of serving as a synthesis of previous contributions.

Keywords: succession having international implications, habitual residence, court, notaries, jurisdiction, Professio iuris.

Sumario: I. Preliminar. II. El litigio y las cuestiones planteadas. III. La sentencia del TJ. 1. Las cuestiones relativas a la aplicabilidad del Reglamento: repercusión transfronteriza de la sucesión y residencia habitual del causante. 2. El notario lituano como tribunal. 3. ¿Pero hubo alguna vez elección de tribunal y elección de ley? IV. A modo de conclusión. 


\section{Preliminar}

1. Con el art. 3.2 del reglamento $650 / 2012^{1}$ puede ocurrir algo parecido a la excepción de orden público, y es que más allá de consideraciones generales en las que no hay debate, va a ser difícil precisar un concepto apriorístico y sin fisuras de "tribunal", ante el cual la tarea de subsunción sea más o menos automática, de manera que el TJ se puede pasar los años venideros declarando qué no es y qué sí es, sin conseguir una definición acabada. De hecho, la sentencia que paso a comentar no difiere mucho de la de 23 mayo $2019^{2}$, y tiene puntos en común -ya tratados- en la de 21 junio $2018^{3}$; en realidad, el Tribunal Supremo lituano podía haber esperado y con la primera de las citadas podía haber resuelto sus dudas, vista la similitud de las tareas de los notarios lituanos y polacos.

2. Es probable que el legislador pecara de optimista y no previera esas dificultades, confiando en la experiencia de otras aproximaciones normativas similares que no han suscitado problemas ${ }^{4}$. Pero las cosas se han ido complicando, porque la calificación no es indiferente en cuanto a criterios de competencia y régimen de reconocimiento de decisiones. Confluyen varios factores: Una norma razonable pero demasiado ambiciosa al adoptar un enfoque funcional, la tremenda disparidad de los ordenamientos nacionales en cuanto a la autoridad encargada de sustanciar las sucesiones, la necesidad de ir diferenciando en razón de la variedad de actos encomendados a esos profesionales del Derecho ${ }^{5}$, la inactividad de los Estados a la hora de cumplir con sus obligaciones de notificación, agravada -entre otras causas- por la doctrina del TJ en WB sobre la ausencia de consecuencias tasadas de tal inactividad ${ }^{6}$. Lo cierto es que la sentencia comentada no zanja ningún problema, y habrá que esperar a la siguiente sobre el mismo tema, que tampoco zanjará el problema.

3. La resolución trata más temas. El orden expositivo de esta nota sigue el de la propia sentencia. Comenzaré refiriendo los hechos en la base del litigio para después comentar cada una de las cuestiones prejudiciales planteadas, si bien alterando el orden en el que figuran en la cuestión prejudicial, agrupándolas en tres bloques: Bases de aplicabilidad del reglamento, concepto de tribunal, correlación forum-ius.

\footnotetext{
${ }^{1}$ Recuérdese su tenor: «A los efectos del presente Reglamento, se entenderá por "tribunal” todo órgano judicial y todas las demás autoridades y profesionales del Derecho con competencias en materia de sucesiones que ejerzan funciones jurisdiccionales o que actúen por delegación de poderes de un órgano judicial, o actúen bajo su control, siempre que tales autoridades y profesionales del Derecho ofrezcan garantías en lo que respecta a su imparcialidad y al derecho de las partes a ser oídas, y que sus resoluciones, dictadas con arreglo al Derecho del Estado miembro en el que actúan:

a) puedan ser objeto de recurso o revisión ante un órgano judicial, y

b) tengan fuerza y efectos análogos a los de la resolución de un órgano judicial sobre la misma materia.

Los Estados miembros notificarán a la Comisión las autoridades y los profesionales del Derecho a que se refiere el párrafo primero, de conformidad con el artículo 79».

${ }^{2}$ Asunto C-658/17, WB.

${ }^{3}$ Asunto C-20/17, Oberle.

${ }^{4}$ Recuérdese el amplio concepto de órgano jurisdiccional del art. 2 del reglamento 2201/2003 y el recogido en el 2.2 del reglamento 4/2009, sustancialmente igual al del reglamento sobre sucesiones, huérfanos de controversia.

${ }^{5}$ Ciertamente complejos, y basta ver los debates que en el ordenamiento español existen al respecto cuando de interpretar las funciones notariales se trata: Vid. F. M. MARIÑo PARDO, "Doctrina y algunas consecuencias sobre las actuaciones de los notarios españoles en el marco del Reglamento 650/2012 a partir de la STJUE de 23 de mayo de 2019”, en La ley Unión Europea, $\mathrm{n}^{\circ}$ 74, 31 de octubre de 2019; I. EsPIÑEIRA SOTO, "Competencia internacional del Notariado Español en expedientes de jurisdicción voluntaria al hilo de una STJUE”, en https://www.notariosyregistradores.com/web/secciones/oficina-notarial/ otros-temas/competencia-internacional-del-notariado-espanol-en-expedientes-de-jurisdiccion-voluntaria-al-hilo-de-una-stjue/

${ }^{6}$ No es baladí que a este tema no se le dedique ni una sola línea en la nota explicativa del Reglamento preparada por B. Hess y otros en 2012 bajo los auspicios del Comité de asuntos legales del Parlamento Europeo, de la misma forma que nada se intuyó al respecto en un texto clave de todo el proceso, H. Dörner/P. LAGARDE, Étude de droit comparé sur les règles de conflits de juridictions et de conflits de lois relatives aux testaments et successions dans les Etats membres de l'Union Européenne, Würzburg, 2002, que sin embargo evidencia perfectamente las diferentes forma de organizar el proceso sucesorio en cada país.
} 


\section{El litigio y las cuestiones planteadas}

4. La sentencia trae causa en la solicitud de E. E. a un notario de Kaunas con el objeto de que se le expidiera, tras el fallecimiento de su madre, un certificado de derechos sucesorios. La causante se había casado con un ciudadano alemán, y se había trasladado a vivir a Alemania. En 2013 otorgó estamento en Lituania, nombrando heredero único de todo su patrimonio a su hijo, nacido de un matrimonio anterior. En 2017 fallece, siendo residente en Alemania, extremo éste que igualmente declaraba en el testamento. Constaba que era propietaria de un inmueble en Kaunas, así como cuentas corrientes en Lituania. Cuando en 2017 el hijo insta la apertura de la sucesión y la expedición de un certificado de derechos sucesorios, le es denegado en base a la falta de competencia, entendiendo que, al estar la residencia habitual de la causante en Alemania, el artículo 4 del reglamento 650/2012 impedía tal apertura. Interpuesto recurso, es estimado por el Tribunal comarcal, apreciando que la causante no había cortado sus vínculos con Lituania, y resolviendo que en base a los principios de razonabilidad y buena fe el notario debía otorgar el acto requerido ${ }^{7}$. Posteriormente, el Tribunal de apelación anula esa resolución, declarando que, cuando el lugar de residencia habitual del fallecido resulta controvertido, sólo un tribunal puede determinar que su residencia habitual radicaba en su Estado de origen, y que, en este asunto, nada indicaba que el recurrente hubiera planteado esa cuestión ante un órgano jurisdiccional; se rechaza además la argumentación del tribunal a quo basada indebidamente en principios generales. Recurrida esta decisión, el Tribunal Supremo de lo civil y penal plantea una extensa batería de cuestiones al TJ: El núcleo central de la sentencia, allí donde pudo aportarse algo más, es la eventual consideración del notario como tribunal -con la consecuencia de que sus actos son resoluciones-, pero comparece también el problema de la definición de la residencia habitual del causante, la internacionalidad de las sucesiones y el juego de la autonomía de la voluntad en la materia (elección de ley y prorrogación de la competencia). Existe una lógica evidente en las preguntas: Dependiendo la competencia de la residencia habitual, los criterios serán unos u otros según estemos ante un notario-tribunal o no, el producto de su actuación circulará por el espacio europeo de un modo u otro según la naturaleza del órgano, cabrá o no electio iuris y su corolario procesal.

\section{La sentencia del TJ}

\section{Las cuestiones relativas a la aplicabilidad del Reglamento: repercusión transfronteriza de la sucesión y residencia habitual del causante.}

5. Lo heterogéneo existe o no existe, pero no se puede discutir mucho sobre ello. Otra cosa es que no se le quiera prestar atención.

A pesar de la presunta complejidad inherente a nuestro peculiar método, en general, la internacionalidad o no de una relación debe condicionar siempre el razonamiento jurídico. Cada vez que algún elemento del supuesto de hecho toque a otra esfera jurídica, al operador no le queda otro remedio que cuestionarse si el legislador le ha querido atribuir transcendencia: Por consiguiente, tan cierto es que si nuestro sistema dictamina que la situación pertenece en exclusiva al Derecho del foro porque a juicio del mencionado legislador la heterogeneidad es irrelevante -y entonces la proyección del método sobre ella no provocará alteración alguna- como que hay sectores en los que la presencia de factores extranjeros tiene consecuencias vitales, y sucesiones es uno de ellos. No hará falta insistir en la transcendencia de este tema de la internacionalidad para el ordenamiento español, donde el art. 9.8 CC (no se olvide, vigente para sucesiones internas pero jurídicamente pluriconectadas) recoge criterios de conexión diferen-

\footnotetext{
${ }^{7}$ El CC lituano establece que el lugar de la apertura de la sucesión es el del último domicilio del causante, y que los herederos pueden instar ante el notario de tal lugar la expedición de una certificación acreditativa de la sucesión, que prueba los hechos consignados en él, retenidos como válidos mientras no se declare la nulidad del documento en el correspondiente procedimiento judicial.
} 
tes, así como una norma de adaptación desconocida en el plano internacional, además de que el notario español puede expedir un CSE sólo si se trata de una sucesión con elemento extranjero ${ }^{8}$.

6. La farragosa formulación de la primera cuestión se resume en la búsqueda de una definición de "sucesión internacional". La respuesta del TJ pasa por recordar que el Reglamento entra en juego en asuntos civiles con repercusión transfronteriza (art. 81 TFUE) y que el elemento crucial es la dispersión entre el Estado de la residencia habitual del causante y algún otro elemento de la sucesión, remitiéndose a los considerandos 23 y 24 del mismo, para concluir que el caso controvertido, en atención a la nacionalidad y residencia del causante, situación de los bienes y de los herederos, encaja en tal noción de sucesión con repercusión transfronteriza. No parece dudoso que las conclusiones del AG se muestran mejor construidas en este tema, hablando de la existencia de vínculos con más de un Estado, en efecto, pero colocando en el centro la residencia habitual del causante, y a partir de ahí señalando que se precisa de la existencia de otros elementos que expresan carácter transfronterizo, que apunta sin tratar de agotar la lista ${ }^{10}$. Porque lo que ha hecho el Tribunal en su motivación es remitirse a la residencia habitual del causante, y los considerandos citados no hacen otra cosa más que interpretar ese concepto y dar pautas para su identificación, mientras que en el fallo realiza un despliegue de indicios colocados en el mismo nivel, omitiendo el papel central de la residencia del difunto, que le habría servido para acuñar una respuesta de amplio alcance.

Cuáles puedan ser esos "elementos de confrontación" es cuestión necesariamente abierta. Las reglas de competencia y las normas de conflicto, al final, vienen a reducir el razonamiento -de hecho- a un par de comprobaciones: Hay elementos que el legislador no ha retenido como relevantes -ni siquiera los ha tenido en cuenta- en el propio texto articulado, aquellos cuya presencia genera internacionalidad real pero cuya toma en consideración al construir una respuesta es eludible por superflua ${ }^{11}$ : La mera dispersión de factores, que sí genera internacionalidad, puede no ser incorporada en la norma como condicionante de la solución. De entre los citados en las conclusiones, ciertamente la situación de los bienes en un Estado distinto al de residencia marca la respuesta jurídica ${ }^{12}$, mas la situación (sic) de los herederos no es relevante sino a los efectos de la realización de ciertos trámites (art. 13), sin alterar el régimen internacional privatístico general; la nacionalidad -presente o pasada- del causante no es per se relevante tampoco, y sólo importa si existe professio iuris, dependiente a su vez de la residencia ${ }^{13}$, mientras que la de los herederos interesaría sólo si la ley reclamada como aplicable por el Reglamento diera cabida a instituciones como el prélèvement o cualquier atribución patrimonial basada en ella, lo que no es sólo que hoy por hoy se halle en franca retirada, sino que resulta incompatible con la unidad

${ }^{8}$ A. Fernandez Tresguerres García, Las sucesiones «mortis causa» en Europa: aplicación del reglamento (UE) $n^{\circ}$ 650/2012, Cizur Menor, 2016, RB-20.10

${ }^{9}$ «¿Debe considerarse que una situación como la controvertida en el presente asunto -en la que una nacional lituana, cuya residencia habitual el día de su fallecimiento estaba probablemente situada en otro Estado miembro pero que, en cualquier caso, nunca había cortado los vínculos con su país de origen y que, entre otras cosas, otorgó testamento en Lituania antes de su fallecimiento y dejó todos sus activos a su heredero, un nacional lituano; en la que en el momento de la apertura de la sucesión se determinó que todo su patrimonio estaba constituido por un bien inmueble ubicado en Lituania, y en la que, por último, el cónyuge supérstite de la causante, nacional de ese otro Estado miembro, manifestó su clara intención de renunciar a la herencia de la fallecida, no participó en el procedimiento iniciado en Lituania y aceptó la competencia de los órganos jurisdiccionales lituanos y la aplicación de la legislación lituana- es una sucesión mortis causa con repercusión transfronteriza en el sentido del Reglamento . $^{\circ}$ 650/2012, a la que debe aplicarse dicho Reglamento?».

${ }^{10}$ Apartado 35: «Sobre cuál pueda ser ese «otro elemento», preceptos singulares del Reglamento retratan hipótesis de sucesión mortis causa con trascendencia en más de un foro, aportando, sin agotar, pautas para reconocer su carácter transnacional. La situación de los bienes, los herederos, los legatarios u otros parientes próximos del causante, así como la nacionalidad de este, son otros tantos datos típicos que se pueden retener».

${ }^{11}$ Evidentemente, la inspiración procede de R. DE NovA, “Quando un contratto è internazionale?", en RDIPP, 1978, pp. 674-675.

${ }^{12}$ Los arts. 10 y 12 ofrecen una respuesta matizada para la competencia judicial internacional que toma en consideración la situación de los bienes, por supuesto siempre en función de la residencia habitual del causante. El art. 30 se mueve en otra dimensión.

${ }^{13}$ Dicho de otra forma, si un ciudadano con nacionalidad extranjera fallece residiendo en España no se plantea un problema de Derecho internacional privado, salvo casos de elección de ley. De la misma manera, sería internacional la sucesión del extranjero que otorga testamento y elige su Derecho como regulador de la sucesión, adquiriendo después la nacionalidad española. 
de régimen jurídico consagrada por el legislador ${ }^{14}$. En consecuencia, parece que lo único en lo que en verdad interesa detenerse es en la residencia y la situación de algunos bienes integrantes del caudal relicto en lugares distintos ${ }^{15}$. Se potencia así la caracterización del Derecho de sucesiones como patrimonial, alejándolo del sector familia, como corresponde a la base jurídica utilizada.

7. La segunda clave es la residencia habitual del difunto, objeto de la quinta cuestión ${ }^{16}$. La idea que apunta el Tribunal lituano (la posibilidad de que una persona tenga dos residencias habituales en atención al mantenimiento por el causante de un vínculo estrecho con el país de la nacionalidad) es evidentemente descartada por el TJ, que se limita a subrayar lo obvio, recordando los considerandos habituales del Reglamento sobre su identificación.

No era necesario detenerse demasiado sobre este punto, más que nada por razones fácticas y de lógica jurídica: a. Siendo el resultado de una evaluación empírica, es imposible que una persona viva simultáneamente en dos sitios: Debe existir una residencia y sólo una, incluso en los casos más difíciles, debiendo ser individualizada sin excusa, no pudiendo saltarse ese paso para realizar directamente la ponderación que comporta la determinación de los vínculos más estrechos, ni dar entrada a la discrecional consideración de otras conexiones existentes con el país en el que uno no vive ${ }^{17} ; \mathrm{b}$. Recuerda la Abogada general que la reconstrucción de la residencia habitual no puede basarse sólo en las meras declaraciones concurrentes realizadas por los particulares ante un profesional que no ejercita funciones jurisdiccionales ${ }^{18}$; con ser ello cierto, no puede olvidarse -a mi juicio- que tampoco deben tener cabida en el Reglamento normas nacionales que resuelvan el problema de la determinación de tal residencia al margen de la estricta atención de los elementos elencados en los considerandos tal y como los interpreta el TJ ${ }^{19}$; c. Desde el momento en que se coloca en el centro del sistema el objetivo de unidad, sólo la identificación de una residencia lo garantiza (al menos entre los Estados vinculados por el texto reglamentario ${ }^{20}$. Aunque el TJ no lo afirme expresamente en la sentencia, la individualización de la residencia es necesaria siempre, incluso cuando se haya elegido la ley rectora de la sucesión, porque funge también como foro de competencia ${ }^{21}$. En este punto, se opera de forma más o menos automática, mecánica, pues resulta diáfano que, aun siendo indubitada cuál sea la residencia habitual, siempre cabrá ponderar vinculaciones, indicios de conexión con otros Estados, pero en una segunda fase, al amparo del art. 21.2.

\section{EI notario lituano como tribunal}

8. La voluntad de no interferir en los sistemas nacionales de tramitación de las sucesiones ${ }^{22}$, y el hecho de que junto a un concepto de tribunal más o menos definido se ofrezca una aproximación que intenta equipararles a otros profesionales, sigue generando dudas. Si careciera de consecuencias el encuadramiento de una concreta figura en esa categoría o no, no pasaría de ser un ejercicio de diletantismo; pero las reglas de competencia son diferentes, y el régimen de circulación de los actos que producen es

\footnotetext{
${ }^{14}$ Otra lectura en J. Carrascosa GonzÁlez, El reglamento sucesorio europeo: Análisis crítico, Murcia, 2019, p. 69.

${ }^{15} \mathrm{La}$ misma idea en la sentencia de 21 junio 2018. Es la que late en la de 1 marzo 2018 (asunto C- 558/16, Mahnkopf), donde el carácter internacional procede de la existencia de un bien en Suecia, teniendo el causante su residencia en Alemania.

${ }^{16}$ «¿Debe interpretarse el artículo 4 del Reglamento n. ${ }^{\circ}$ 650/2012 (o cualquier otra de sus disposiciones) en el sentido de que la residencia habitual del fallecido solo puede estar situada en un Estado miembro concreto?».

${ }^{17}$ Considerando 25.

${ }^{18}$ Conclusiones, párrafo 50 .

${ }^{19}$ Como parece hacer el art. 5.4 del CC lituano.

${ }^{20}$ El párrafo 41 de la sentencia recoge las observaciones del párrafo 44 de las conclusiones de la AG, deslizando sin embargo una afirmación precipitada a mi juicio, al decir que si se admitiera la posibilidad de varias residencias simultáneas se abocaría en fragmentación y se privaría de sentido a una buena parte de los artículos del Reglamento. Olvidan la norma sobre litispendencia, idónea para evitar los inconvenientes derivados de la apertura en paralelo de la sucesión en dos Estados miembros. Probablemente es todo tan sencillo y limitado como excluir lo ontológicamente imposible.

${ }^{21}$ Piénsese que cuando se habla de ley aplicable la transcendencia de la determinación del criterio de conexión principal palidece ante la posibilidad de usar la cláusula de escape.

${ }^{22}$ Considerandos 20 y 21.
} 
distinto, como es sabido. El problema nunca surge en abstracto, porque los profesionales del Derecho con atribuciones en este sector despliegan un amplio abanico de actuaciones, y operan de forma muy distinta según de cuál se trate ${ }^{23}$, y por eso no caben inclusiones y exclusiones tajantes ${ }^{24}$. Así las cosas, es de frente a una concreta modalidad de actuación del notario cuando se han planteado las incertidumbres, en supuestos bastante parecidos hasta ahora (en WB era un certificado de título sucesorio, con valor probatorio de los derechos del heredero; en EE se trataba de un certificado de derechos sucesorios, acreditativo de los hechos consignados en él). Las cuestiones segunda, tercera y cuarta inquieren si tal actuación es propia de un tribunal, si en consecuencia los actos emanados son resoluciones y si, en caso de no ser así, son documentos públicos ${ }^{25}$.

9. El TJ argumenta que esta actuación notarial consistente en la expedición de un certificado de derechos sucesorios no constituye ejercicio de función jurisdiccional, a partir de las siguientes premisas: a) el tenor del art. 3.2 del reglamento y del considerando 20 del reglamento, que en todo momento asumen como eje la noción de función jurisdiccional, de forma tal que el concepto de tribunal comprende no sólo a las autoridades judiciales sino también a otros profesionales del Derecho con competencias en la materia; b) irrelevancia de la falta de comunicación de los Estados de quiénes son esas autoridades y profesionales, prevista en esa misma norma ${ }^{26}$; c) equiparación de ejercicio de funciones jurisdiccionales a competencia en caso de controversia, con independencia de que se trate de jurisdicción contenciosa o graciosa ${ }^{27}$. Teniendo en cuenta que el notario lituano se limita a establecer los derechos subjetivos no discutidos, que no resuelve aspectos controvertidos ni fija elementos de hecho que no sean claros y evidentes ni se pronuncia sobre hechos objeto de controversia (art. 1 de la Ley del notariado), la proyección de tales premisas conduce a tal respuesta negativa, sin perjuicio del apabullante ejercicio de nadar y guardar la ropa que sigue de inmediato: En todo caso, el órgano remitente ha de comprobar aquel extremo, así como el hecho de que eventualmente actúen por delegación o bajo control de un tribunal. Va

${ }^{23}$ En España, las formas de actuación notarial son sistematizadas en cuatro grupos: Aquellas que comportan el ejercicio de funciones jurisdiccionales, de constatación de hechos y emisión de una calificación jurídica, de autentificación y de recepción de declaraciones: I. EsPIÑEIRA Sото, "Competencia internacional del Notariado Español en expedientes de jurisdicción voluntaria al hilo de una STJUE”, en https://www.notariosyregistradores.com/web/secciones/oficina-notarial/otros-temas/competencia-internacional-del-notariado-espanol-en-expedientes-de-jurisdiccion-voluntaria-al-hilo-de-una-stjue/

${ }^{24}$ Consecuenctemente, no se puede pretender una calificación unívoca de la actuación notarial.

Los pronósticos, por ello, han estado lejos de cumplirse: A. Fernández Tresguerres, "Aplicación notarial del Reglamento comunitario sobre sucesiones mortis causa", en Escritura pública, 77, 2012, pp. 40-41, confiando todo en las notificaciones estatales y en las comprobaciones de veracidad que realice la Comisión; J. CARrascosa GonZÁlez, "Reglamento sucesorio europeo y actividad notarial", en CDT, 2014, p. 14; A. Bonomi/P. WAUtelet, "Comentario al art. 3", en El Derecho europeo de sucesiones. Comentario al reglamento (UE) $n^{\circ}$ 650/2012, de 4 de julio de 2012, Cizur Menor, 2015, párrafo 76.

${ }^{25}$ «2) ¿Debe considerarse que el notario lituano que abre la sucesión, expide un certificado de derechos sucesorios y realiza otras actuaciones necesarias para que el heredero pueda hacer valer sus derechos, es un "tribunal" en el sentido del artículo 3 , apartado 2, del Reglamento n. $^{\circ}$ 650/2012, teniendo en cuenta que, en el desempeño de sus funciones, los notarios respetan los principios de imparcialidad e independencia, sus decisiones son vinculantes para ellos y para las autoridades judiciales y sus actos pueden ser objeto de control judicial?

»3) En caso de respuesta afirmativa a la segunda cuestión prejudicial, ¿deben considerarse los certificados de derechos sucesorios expedidos por los notarios lituanos como resoluciones en el sentido del artículo 3, apartado 1, letra g), del Reglamento n. ${ }^{\circ}$ 650/2012, de modo que es preciso determinar la competencia para su emisión?

»4) En caso de respuesta negativa a la segunda cuestión prejudicial, ¿deben interpretarse los artículos 4 y 59 del Reglamento.$^{\circ}$ 650/2012 (conjuntamente o por separado, si bien sin ánimo exhaustivo) en el sentido de que los notarios lituanos están facultados para expedir certificados de derechos sucesorios sin atenerse a las normas generales sobre competencia y de que esos certificados han de ser considerados documentos públicos que surten efectos jurídicos en otros Estados miembros?».

${ }^{26}$ «La circunstancia de que una autoridad nacional no haya sido mencionada no basta, por sí sola, para concluir que esa autoridad no cumple los requisitos contemplados en el artículo 3, apartado 2, de dicho Reglamento» (párrafo 43).

${ }^{27}$ Conviene recordar que en la sentencia WB ya se habían alcanzado conclusiones en el mismo sentido: Sólo los tribunales emanan resoluciones, las listas de autoridades que ejercen funciones jurisdiccionales enviadas por los Estados constituyen sólo una presunción, función jurisdiccional es resolver en virtud de la propia potestad sobre los puntos controvertidos, sea jurisdicción contenciosa o voluntaria, resolver litigios (párrafo 55, con cita de jurisprudencia en el mismo sentido), no se ejercita tal función cuando la competencia del notario depende exclusivamente de las partes. El argumento derivado de la remuneración según baremo es a mi juicio olvidable, porque toca al aspecto orgánico y no al funcional (de hecho, ya no ha vuelto a esta sentencia, a diferencia de los demás). 
de suyo que la respuesta a las cuestiones sucesivas queda condicionada por lo anterior, sin sorpresas: i) Sólo los tribunales dictan resoluciones (art. 3.1.g) ${ }^{28}$; en todo caso, si el órgano judicial remitente considera que el notario lituano ha actuado como tribunal, el certificado expedido tendrá la consideración de resolución y a los efectos de su expedición puede (no es una errata: en las demás versiones lingüísticas también se emplea el verbo poder, sin ofrecer mayores explicaciones o guías de interpretación) aplicar las normas de competencia del capítulo II del Reglamento; ii) cuando el notario no actúa como tribunal en el acto de emitir un certificado sucesorio nacional no tiene que ajustarse a las normas reglamentarias de competencia, correspondiendo al tribunal nacional la verificación de que tal certificado es un documento público conforme a las reglas del art. 3.1.i del Reglamento, idóneo para producir en el resto de Estados miembros los efectos que les vincule el Derecho del Estado de origen o los más próximos.

10. La parte mollar de la sentencia es claramente la relativa a la consideración del notario como tribunal. No es sólo que sea un tema actualmente abierto, sino que de ahí dependen los desarrollos sucesivos. En este tema calificatorio hemos asistido al paso de una visión orgánica e institucional -la desarrollada a partir del art. 267 TFUE, a propósito de la legitimación para formular cuestiones prejudiciales $^{29}$ - a otra más atenta a la función, propia de los instrumentos de Derecho internacional privado ${ }^{30}$. El legislador asume la infraestructura organizativa preexistente, consciente de que en bastantes países de Europa las tareas propias del Derecho de sucesiones son desarrolladas en muy buena medida por instancias distintas a las judiciales, y justamente por ello no pudo prescindir, en particular, del notaria$\mathrm{do}^{31}$. La cuestión es saber en qué condiciones encajan estos profesionales en el RS. En atención a los objetivos perseguidos en esa norma y en estos reglamentos (cooperación del TJ con los órganos judiciales nacionales en aras de una correcta interpretación y aplicación del Derecho de la Unión frente a la realización de los derechos de los particulares con consiguiente eliminación de los obstáculos a la libre circulación: o sea, flexibilidad cooperativa frente a rigurosidad procedimental), no se podía trasladar sin más la noción acuñada respecto a las cuestiones prejudiciales, de la misma manera que no cabe extraer de los reglamentos administrados por jueces que resuelven contenciosos directrices válidas para estos otros que operan sobre una base de profesionales y procedimientos completamente diversos. La aproximación del art. 3.2 es coherente por ser flexible, respetuosa con el entramado normativo del que se parte y con las exigencias de rigor inherentes a la circulación de resoluciones. La solución del TJ en el caso concreto no podía ser otra si quería respetar su tenor, pero cuando se eleva la mirada quedan algunas cuestiones abiertas:

— La definición de función jurisdiccional. El art. 3.2 distingue dos categorías de tribunales, los genuinos (o sea, los órganos judiciales) y los asimilados por razón de la concurrencia de ciertos elementos definitorios que los aproximan a los primeros ${ }^{32}$. Es la identificación de éstos la que genera dudas de interpretación, porque la definición legal está demasiado poco perfilada, dependiente en primer lugar de qué se entienda por "ejercicio de funciones juris-

\footnotetext{
${ }^{28}$ Resolución es decisión, dice la sentencia de 23 mayo 2019.

${ }^{29}$ Sobre este tema, vid. J. Rodriguez Medal, "Concept of a Court or Tribunal under the Reference for a Preliminary Ruling: Who can refer Questions to the Court of Justice of the EU?", en European Journal of Legal Studies, 2015, pp. $111 \mathrm{ss.}$

${ }^{30} \mathrm{La}$ evolución posterior del Derecho de la UE va en este sentido, como acreditan los arts. 3.2 de los reglamentos 1103 y 1004 de 2016. Conviene por tanto aportar guías claras al respecto.

31 J. Gómez-Riesco Tabernero de Paz, "Réflexions sur la notion de "juridiction" au sens de l'article 3.2 du règlement (UE) $n^{\circ}$ 650/2012 après les arrêts de la Cour de Justice de l'Union Européenne Oberle, C-20/17, et WB, C-658/17. Perspective espagnole", en $C D T, 2020$, p. 1002.

${ }^{32}$ El tipo de profesional que se tuvo en mente en el momento de la elaboración del Reglamento es el del notario designado por el tribunal y que actúa como delegado (casos austriaco, checo o húngaro por ejemplo), pero la definición legal desborda ampliamente este modelo. La información es recogida por M. REQUEJo IsIDRo, "El artículo 3, apartado 2, del Reglamento $\mathrm{n}^{\circ}$ 650/2012: autoridades no judiciales y otros profesionales del Derecho", en REEI, 2020, no 39, p. 3, con cita del documento interinstitucional 2009/0157 (COD), de 6 de mayo de 2011, punto 17. Sobre esos profesionales son muy útiles las informaciones contenidas en P. Beaumont/J. Fitchen/J. Holliday, The evidentiary effects of authentic acts in the Member States of the European Union, in the context of successions, estudio elaborado bajo los auspicios del Parlamento Europeo en 2016, disponible en https://www.europarl.europa.eu/cmsdata/131000/juri-committee-study-successions-authentic-acts.PDF.
} 
diccionales". Y es en este punto donde el TJ termina por equiparar tribunal a controversia: No se ejerce jurisdicción si no se resuelven litigios ${ }^{33}$. Es cierto que jurisdicción y conflicto son términos tradicionalmente unidos, mas se olvida que a veces una instancia integrada en la estructura orgánica de la jurisdicción estatal en algunos casos no resuelve controversia alguna, y sigue siendo un genuino tribunal, y de hecho el $\mathrm{TJ}$ ha aseverado que es indiferente que se trate de jurisdicción voluntaria o contenciosa, de manera que está admitiendo que en aquellos casos en los que un juez se limita a constatar unos hechos y existe acuerdo entre las partes también hablamos de tribunal y que se emanan resoluciones ${ }^{34}$. Nuestra Ley de jurisdicción voluntaria, donde la existencia de controversia no convierte en contencioso al expediente (art. 17), ofrece ejemplos elocuentes de procedimiento judicial en temas sucesorios sin contraposición de intereses individuales (arts. 91 ss.), supuestos respecto de los que nadie dudaría que estamos ante un tribunal emanando resoluciones en los términos del art. 3.2 del Reglamento ${ }^{35}$. La existencia de controversia, pues, no puede convertirse en el elemento definitorio determinante, porque en buena medida vacía de contenido aquella disposición: De hecho, en Oberle se dijo que el tribunal alemán estaba vinculado a las normas de competencia del Reglamento en la emisión de un certificado sucesorio nacional ${ }^{36}$. Habría, pues, que plantear la idoneidad de superar esa ecuación, poniendo en un primer plano la cuestión de si es necesaria la intervención de una autoridad, única en condiciones de dar nacimiento a situaciones de las que se derivan derechos y obligaciones ${ }^{37}$. Cuando las partes no pueden autónomamente intervenir para moldear la realidad jurídica porque el sistema jurídico los somete a respaldo o control mediante un juicio autónomo independiente y no predeterminado -y siempre que el profesional no esté completamente vinculado por las manifestaciones o solicitudes de las partes, ni sujeto a su aprobación o consentimiento-, se está ejerciendo la función jurisdiccional en el sentido del Reglamento. Cuando su intervención se limita a un control de legalidad y su potestad queda reducida a la posibilidad de negarse a otorgar un documento, hablamos sólo de autenticación ${ }^{38}$.

- La unidad de tratamiento jurídico de los actos. Téngase presente que la distribución de competencias en algunos ordenamientos estatales supone encomendar el grueso de la gestión de las sucesiones a órganos no judiciales; en España alguno de esos actos encomendados a los secretarios judiciales (tribunales genuinos en definitiva) pueden ser realizados también por otros profesionales a los que con el objetivo de aliviar la carga de trabajo de los primeros y agilizar los mecanismos de tutela de los derechos individuales se encomienda su confección: Así pues, sería paradójico que un mismo acto se sometiera a normas de competencia y circulación diferentes, con distinta naturaleza según cuál fuera el cauce escogido por las

${ }^{33}$ Es la más que famosa sentencia de 2 junio 1994, asunto C-414/92, Solo Kleinmotoren c Boch. Más específicamente en la de 9 febrero 2017 (T-271/15 P) participa de la misma idea de base al excluir del núcleo de las autoridades públicas a los notarios húngaros, cuyas decisiones se basan en el consentimiento de las partes.

${ }^{34}$ Vid. considerando 59. Una interpretación restrictiva en M. J. CAstellanos Ruz, "Competencia internacional en materia de expedición de certificados sucesorios: A propósito de la sentencia del TJUE 21 junio 2018, Vincent Pierre Oberle, C-20/17”, en $C D T, 2020$, p. 481.

${ }^{35}$ Piénsese por ejemplo en la autorización al albacea para disponer de bienes de la herencia, o en el nombramiento de un contador partidor dativo.

${ }^{36}$ Con una diferencia, y es que el notario lituano "realiza otras actuaciones necesarias para que el heredero pueda hacer valer sus derechos", según aparece formulada la cuestión: Cfr. C. SANTALó Goris, "The Court of Justice on the Succession Regulation”, en https://eapil.org/2020/10/21/the-court-of-justice-on-the-succession-regulation-carlos-santalo-goris-on-the-e-e-case/

${ }^{37}$ La jurisprudencia del TEDH muestra cómo no es imperativo que lo que llamamos tribunal esté integrado en la estructura orgánica de la judicatura. Lo importante es el respeto de las exigencias derivadas de la independencia, imparcialidad y equidad, sin importar que las competencias sean materialmente limitadas. Es igualmente inherente a su función decidir con fuerza obligatoria, y que sólo otro tribunal pueda modificar lo acordado. Una completa recopilación en COUR EUROPÉENNE DES DROITS DE L'HOMme, Guide sur l'article 6 de la Convention européenne des droits de l'homme. Droit à un procès équitable, edición cerrada a 30 de abril de 2020 , pp. 36 ss.

${ }^{38}$ Que es lo que ocurría en WB, donde el TJ firmemente declara que el notario polaco no es un tribunal, como recuerda $\mathrm{F}$. M. MARIÑo PARDO, "De nuevo sobre la actuación notarial en el marco del Reglamento europeo de sucesiones", en La Ley Unión Europea, $\mathrm{n}^{\circ} 85,1$ de oct. de 2020, p. 46 
partes $^{39}$. Parece razonable, por tanto, que los actos en los que concurran tribunales y otros profesionales se sometan a idéntico régimen internacional privatístico, evitando incoherencias y el riesgo de forum shopping ${ }^{40}$.

- La certeza de los criterios de competencia. Admitamos que al particular le da exactamente igual que un notario sea considerado tribunal o no; lo que le interesa es la eficacia transfronteriza de lo que produzca. Desde este punto de vista no es tan importante la calificación, porque documentos y resoluciones gozan a priori de tal eficacia. Pero ya sabemos que las normas de competencia y de circulación son distintas, así que desde el punto de vista de las consecuencias se constata cómo la interpretación expansiva del concepto profesionales que ejercen funciones jurisdiccionales se traduce en la extensión del juego de las normas de competencia judicial del reglamento, y consiguientemente la reducción de los supuestos en los que se aplican las normas de origen interno, con lo que ello supone de inseguridad, incertidumbre, incremento de los costes de información a cargo de los particulares.

- Y las demás garantías. Todo ello no es más que un primer paso en la depuración del concepto. Interpretando en atención a los objetivos del Reglamento, que culminan en la elaboración de productos jurídicos exportables, es irrenunciable salvaguardar el rigor en la defensa de los derechos de defensa en origen ${ }^{41}$. Queda por ello pendiente la comprobación de los requisitos previstos en el art. 3.2: Garantías de imparcialidad y del derecho de audiencia de las partes, y que sus resoluciones puedan ser objeto de recurso o revisión ante un órgano judicial y tengan fuerza y efectos análogos a los de la resolución de un órgano judicial sobre la misma materia. Permítaseme recordar que al menos desde el punto de vista del Derecho español, de cara a la actuación del notario como tribunal se trata de requisitos cuya concurrencia es incuestionable ${ }^{42}$. Sea como fuere, permanece el interrogante de qué puede hacer un tribunal al que se le aporta un formulario del anexo I del reglamento de ejecución 1329/2014, redactado por un profesional que se autocalifica como tribunal. Respuesta: Salvo error mío, nada. En la sentencia WB era el órgano del Estado de origen el que se negaba a expedirlo, amparándose en el hecho de no figurar entre los asimilados a tribunal en la declaración estatal. Pero en vista de la jurisprudencia del TJ, que como veremos de inmediato no concede demasiado valor a estas listas, la falta de comunicación a la Comisión no vincula a los operadores jurídicos, de forma que cada profesional es el único juez de su adecuación a los requisitos del art. 3.2, pudiendo proceder a la extensión del formulario primero o segundo según entienda. Pues bien, no parece que el Reglamento ofrezca instrumento alguno para hacer frente a estas patologías. Reténgase que: a) Hay elementos de la definición que son inverificables en esa fase procesal (el ejercicio de la función jurisdiccional, por ejemplo). El principio de la confianza recíproca impide controlar si se debió extender o no el mentado formulario ${ }^{43}$; b) Otros presupuestos sólo pueden chequearse de

${ }^{39}$ Se hace referencia a lo tocante a albaceas, contador partidor y aprobación de la partición. Sobre este aspecto, J. GómEZ-RIESco Tabernero de Paz, "Réflexions..., op. cit.”, p. 1009; M. J. Castellanos Ruiz, “Competencia internacional..., op. cit.”, p. 490.

${ }^{40}$ La exposición de motivos de la LJV explica que por razones de utilidad se ha considerado constitucionalmente legítimo encomendar a órganos diferentes de los jueces la tutela de algunos derechos que hasta ahora se integraban en la esfera de la jurisdicción voluntaria. Cambia exclusivamente la identidad del órgano, pero no los intereses tutelados ni la garantía de los derechos, por lo que no tiene sentido afirmar que la naturaleza del acto en cuestión se ha transformado. En consecuencia, si antes era sin duda un tribunal quien los generaba, ahora debe recibir la misma calificación el profesional encargado.

${ }^{41}$ De independencia, imparcialidad y contradicción en la actuación de la Administración de justicia como base de la confianza recíproca habla el TJ en su sentencia de 9 marzo 2017, asunto C 484/15, Ibrica Zulfikarpašić c Slaven Gajer, a propósito del reglamento 805/2004. Es interesante constatar cómo la reciente sentencia de 21 enero 2020 (C-274/14) resume los elementos definitorios, poniendo el acento en la independencia.

42 J. Gómez-Riesco Tabernero de Paz, "Réflexions...", op. cit., pp. 1016 ss.

${ }^{43}$ Ya sé que es otro ámbito, pero lo que se asevera en la sentencia de 22 diciembre 2010 (Aguirre c. Pelz) vale con alcance general: Son las partes las que deben velar por el cumplimiento de la legalidad vigente, y litigar en el Estado de origen si consideran que un formulario o una certificación está indebidamente expedido. 
forma indirecta, como motivos de denegación del art. 40 (orden público como sanción de la falta de respeto de las garantías procesales) $)^{44}$.

- La lista inacabada de autoridades. La falta de sanción a la pasividad estatal tiene consecuencias perversas ${ }^{45}$. Si las notificaciones estatales sólo dan lugar a presunciones iuris tantum, quiere decir que al margen de ellas hay espacio para descubrir ejercicios de función jurisdiccional, y que incluso lo notificado por los Estados es irrelevante, condicionado a un análisis caso por caso $^{46}$. Se aboca a la justicia del cadí, existiendo como existen discrepancias en cuanto a la calificación de las actuaciones notariales. Hay inexactitudes por exceso y por defecto: Reténgase que algunos países no han notificado nada, como era el caso resuelto en el asunto comentado ${ }^{47}$. El ejemplo del ordenamiento español, en el que se ha incluido en ese concepto de tribunal la actuación de los notarios en asuntos en los que tienen competencia exclusiva y se ha dejado fuera otros en los que se dan los requisitos del mencionado art. 3.2, es elocuente ${ }^{48}$. Y queda además la cuestión de la implementación del control de veracidad y corrección: Es esencial para el goce de la seguridad jurídica poder conocer desde el principio cuál es el camino a recorrer. Que tenga que ser el TJ el que vaya precisando en cada caso qué entra y qué no en esa norma comporta un riesgo de sobrecarga de trabajo, de que demasiadas cosas escapen a ese control y de dilaciones insoportables. No es la mejor solución, pero en el momento de acudir a una autoridad debería ser posible confiar en lo publicado ${ }^{49}$.

- Corolario: Al final queda la duda de si no habría sido más oportuno interferir en la ordenación nacional de la función de esos otros profesionales y por ello crear criterios de competencia también para su actividad. La variedad de formas de actuación de un notario -figura paradigmática en este punto- dentro incluso de un mismo ordenamiento, convierte en tarea de extraordinaria complejidad el intento de arrojar luz al contenido del art. 3.2. El legislador quería minimizar la incertidumbre, se asegura. Pues que empiece a subsanar.

11. Ya se ha dicho que a partir de la no consideración del notario lituano como tribunal todo se desenvuelve fluidamente. No emana resoluciones, pero sí documentos públicos. Las afirmaciones del TJ son lógicamente inobjetables. Las indicaciones que constan permiten comprobar que se reúnen las condiciones de control de identidades y contenido e intervención de una autoridad: La definición que frece el art. 3.1.i se ajusta sin dificultad al notariado latino. Poco más hay que añadir.

\footnotetext{
${ }^{44}$ Cfr. M. ReQUeJo IsidRo, "El artículo 3, apartado 2, del Reglamento no 650/2012..., op. cit.”, p. 13.

${ }^{45}$ El párrafo 46 de la sentencia es desolador, porque se limita a recordar lo obvio, esto es, que el objetivo reglamentario de asegurar la correcta administración de justicia en la UE se vería seriamente amenazado si cada Estado miembro pudiera determinar la calificación de lo que se considera tribunal a los efectos del art. 3.2 mediante la abstención de notificar o comunicando lo que no corresponde. Pero a partir de ahí, nada de nada. Sigue siendo un arcano saber en qué se traducirá ese incumplimiento de los Estados.

${ }^{46}$ Sobre tales falsas impresiones, E. Castellanos Ruiz, "Ley aplicable a la sucesión mortis causa", en A. L. CAlvo Caravaca/J. Carrascosa González, Litigación internacional en la Unión Europea IV. Comentario al Reglamento UE núm. 650/2012 del Parlamento Europeo y del Consejo sobre sucesiones mortis causa, Cizur Menor, 2019, p. 134. Añádase el riesgo de error en la transcripción de las comunicaciones estatales y se culmina el círculo de la inanidad.

${ }^{47}$ Eslovaquia, Rumanía, Polonia, Austria, Holanda, Malta, Luxemburgo, Lituania, Italia, Francia, Estonia, Alemania, Bélgica no responden o comunican que no existen tales autoridades. Chipre, Eslovenia y Bulgaria explican que sólo los órganos judiciales reúnen la condición de tribunal a los efectos del art. 3.2. A la luz de la doctrina del TJ, todas esas afirmaciones son irrelevantes. Por su parte, las comunicaciones húngara o la croata (los notarios son esas otras autoridades, vienen a decir) son tan genéricas que exigirán una depuración en función del tipo de acto que realicen; la griega es un minitratado sobre la función notarial y su idoneidad para emanar... ¡idocumentos públicos!

${ }^{48}$ Habría que plantear la inclusión de las actuaciones contempladas en el art. 66.2 de la Ley notarial, relativas al albaceazgo y al contador partidor dativo, y la exclusión de lo relativo a apertura, adveración, protocolización de los testamentos no notariales, donde el control es solo formal: $C f r$. F. M. MARIÑo PARDO, "Doctrina y algunas consecuencias..., op. cit.". Por su parte, el considerando 63 del Reglamento parece asumir que una declaración de herederos no la realiza un tribunal, porque es un documento público.

${ }^{49}$ Algún día la Comisión iniciará un procedimiento de infracción por incumplimiento de las obligaciones de comunicación de los Estados.
} 


\section{3. ¿Pero hubo alguna vez elección de tribunal y elección de ley?}

12. La última cuestión afecta a la eventual existencia de professio iuris sucesoria y en consecuencia la posibilidad de elegir el tribunal competente ${ }^{50}$. Vaya por delante que cabría apreciar cierto divorcio entre los desarrollos contenidos en la motivación y el fallo, que no es más que una obviedad: «Los artículos 4, 5, 7, 22 y 83, apartados 2 y 4, del Reglamento n. ${ }^{\circ}$ 650/2012 deben interpretarse en el sentido de que la voluntad del de cuius y el acuerdo entre los llamados a sucederlo pueden llevar a la determinación de un tribunal competente en materia de sucesiones y a la aplicación de una ley sucesoria de un Estado miembro distintas de las que resultarían de la aplicación de los criterios dimanantes de dicho Reglamento». Eso ya lo dicen las normas, así que para este viaje no hacía falta tantas alforjas. Si algún interés tiene la sentencia es por lo que precede al fallo, pues.

13. A juicio de quien esto firma, el TJ ha razonado al revés de cómo se exige en el Reglamento, que parte de la constatación de la elección del Derecho de la nacionalidad del causante como presupuesto imprescindible para que los interesados puedan elegir el foro (art. 5). Son dos operaciones indisociables con un orden preciso; dar una impresión diferente no es técnicamente correcto. Sin tal elección, no ha lugar a prorrogación alguna, lo que nada tiene que ver con la facultad indiscutida de resolver el asunto extrajudicialmente en el país que prefieran los interesados. Sea como fuere, la Corte razona afirmando que: a) En el presente caso no consta que las partes en el procedimiento sucesorio hayan celebrado un acuerdo sumisorio conforme a los requisitos del art. 7; b) no obstante, el cónyuge supérstite de la causante había declarado que admitía la competencia de los tribunales lituanos; c) el órgano judicial nacional debe comprobar si eso equivale a un acuerdo de elección de tribunal.

Pues bien, no parece que el legislador haya querido dar validez a acuerdos informales de prorrogación: El considerando 28 es elocuente, sin ofrecer la más mínima traza de flexibilización de las exigencias formales previstas en el art. 5.2. La AG recordaba que la aceptación de la competencia debía ser expresa ${ }^{51}$, que el art. $7 \mathrm{c}$ ) se refiere a las partes en el proceso que aceptan la competencia del tribunal ante el que se esté sustanciando la sucesión (lo que no era el caso, porque no parece que el viudo estuviera implicado en litigio alguno) y que no cabe confundir las dimensiones procesal y sustantiva, que las afirmaciones requeridas deben proyectarse específicamente sobre la elección del foro, sin que tenga incidencia lo que alguien pueda proclamar sobre sus eventuales derechos sucesorios ${ }^{52}$. El TJ ha espiritualizado tanto las exigencias de forma que ha terminado por eludir las previstas en la ley, de forma que se abre la puerta a que en el futuro un tribunal nacional descubra la existencia de un acuerdo a partir de comportamientos o de documentos ajenos al procedimiento sucesorio.

14. En cuanto a la elección de ley, el objetivo es, como señaló la AG en sus conclusiones, huir de una lectura formalista del Reglamento, pero no puede serlo inventar una manifestación de voluntad cuando no la hubo. En la medida en que no se puede ya contar con la asistencia del testador para conocer sus deseos e intenciones, éstas deben resultar de manera clara a partir de los elementos escritos en presencia. Tratándose de un testamento otorgado antes de 17 de agosto de 2015, el TJ se apoya en el art. 83 del Reglamento para encomendar al tribunal nacional la tarea de verificar si se otorgó conforme a la ley elegible, esto es, la lituana. Existen dos reconstrucciones en este punto, y de nuevo son esas conclusiones las que centran mejor el tema (salvo un borrón al final ${ }^{53}$ ): a) No cabe inferir la professio

\footnotetext{
${ }^{50}$ «¿Deben interpretarse y aplicarse los artículos 4, 5, 7 y 22 del Reglamento n. ${ }^{\text {o }}$ 650/2012 (conjuntamente o por separado, si bien sin ánimo exhaustivo) de un modo que, en el presente asunto, sobre la base de los hechos descritos en la primera cuestión prejudicial, deba concluirse que las partes de que se trata aceptaron la competencia de los órganos jurisdiccionales lituanos y que se aplicara la legislación lituana?». Permítaseme sugerir que se trata de una cuestión hipotética, en la medida en que alude a extremos no controvertidos. La verdad es que la respuesta es igual de hipotética, pero nunca, creo, debió ser admitida esta cuestión.

${ }^{51}$ En el párrafo 119 de las conclusiones.

52 «...la declaración que una parte interesada realiza fuera de cualquier proceso sobre sus derechos u obligaciones en relación con la herencia tampoco provoca el efecto sumisorio»».

${ }^{53}$ No se puede decir (párrafo 107 y conclusión sexta) que en testamentos previos a 17 de agosto de 2015 en los que no conste elección de ley cabe acoger la ficción de que hubo tal elección si el testamento es válido conforme a la ley nacional del causante, salvo que se quiera decir que la única forma de salvar la validez sea aplicar esa ley. Porque si una disposición testa-
} 
iuris de datos externos al propio testamento, y más cuando resulta que se ha acudido a un notario que seguramente habrá asesorado a la testadora en cuanto a sus posibilidades en el plano conflictual; b) Los factores externos a la disposición testamentaria (como, por ejemplo, el hecho de que el causante se hubiera desplazado a su país para otorgar testamento, la nacionalidad de la autoridad interviniente o cuál sea el ordenamiento que le inviste de competencia) no son decisivos, porque si hubo o no elección de ley debe deducirse directamente de la propia disposición testamentaria.

Frente a la mesura de esta argumentación, el TJ viene a aseverar que, supuesto que se pudo hacer una cosa, se hizo: Como la ley lituana era elegible, concluye, fue elegida ${ }^{54}$. Además, un recordatorio extemporáneo sobre la voluntad de legislador de que la autoridad aplique su propia ley. Y hasta ahí. Evidentemente cabe una elección tácita de la ley, pero debe basarse en datos ciertos. En cambio, ninguna referencia a las reglas o instituciones específicas del ordenamiento lituano, a expresiones exclusivas de ese sistema, incluso a la nulidad del testamento si se aplicara la ley de la última residencia habitual, cualquier otro indicio deslizado en aquel. Ni que decir tiene que la universalización de esa forma de construir conduce a conclusiones bastante endebles, porque no siempre se hace lo que la ley permite hacer ${ }^{55}$. Es la esencia de la autonomía (o el resultado de un deficiente asesoramiento).

\section{A modo de conclusión}

15. La lectura de la sentencia del TJ de 16 julio 2020 permite extraer a mi entender cuatro enseñanzas básicas:

a. Implicaciones transfronterizas las tiene toda relación con dispersión de elementos, pero el Reglamento les da relevancia y deduce consecuencias diferenciadas sólo cuando la residencia habitual del causante y los bienes que forman parte del caudal relicto se encuentren en Estados diferentes. Otros indicios son descartados por el legislador.

b. La definición de "tribunal" en el sentido del art. 3.2 del Reglamento no puede pivotar sobre la existencia o no de controversia, porque supondría un vaciamiento de su contenido. Parece más razonable poner el foco en la necesidad de intervención de una autoridad con funciones que vayan más allá de la mera constatación de hechos.

c. Dejar en manos de los Estados la lista de esas otras autoridades que ejercen funciones jurisdiccionales no aporta seguridad: Ni está todo lo que debe estar ni es seguro que no sobre nada en ella. En realidad, ni siquiera es posible elaborarla, porque interesan actos, no profesionales. El catálogo, pues, no es sino una promesa de estabilidad, con horizonte inaprehensible.

d. La creatividad del TJ en el tratamiento de la autonomía de la voluntad es bien intencionada pero constituye un caso de exuberancia judicial. No es que en el caso concreto se haya flexibilizado los requisitos normativos, sino que se realizan declaraciones con alcance general que invitan a convertir las ficciones en normas.

O sea, a base de remisiones a los órganos nacionales, reiteración de vaguedades e interpretaciones claramente carentes de sólido sustento normativo, lo único que cabe decir con certeza es que hoy no estamos mejor que el día 15 de julio de $2020^{56}$

mentaria es válida tanto conforme a la ley de la última residencia habitual del causante como a la de su nacionalidad, y no es diáfano que se eligiera esta última, nada autoriza a acoger tal ficción.

${ }^{54}$ «Este precepto puede aplicarse en el caso de autos, dado que, por una parte, el testamento de que se trata en el litigio principal se realizó antes del 17 de agosto de 2015 y, por otra parte, podía elegirse la ley lituana, de conformidad con el artículo 22 , apartado 1, párrafo primero, del Reglamento n. ${ }^{\circ} 650 / 2012$, puesto que la causante poseía la nacionalidad lituana en el momento en que se realizó dicho testamento. Por consiguiente, ha de reputarse que esta ley, con arreglo a la cual se realizó el testamento, fue elegida como ley aplicable a la sucesión objeto del litigio principal» (párrafo 94).

${ }^{55}$ Como recuerda M. LeHMANN en su comentario a la sentencia de referencia, «[i]n future cases, it will be sufficient to prove that the will has been made before a notary of a certain Member State in order to show that the deceased chose the law of this Member State»: Vid. en https://eapil.org/2020/10/21/a-major-cjeu-decision-on-the-succession-regulation-the-case-of-e-e/

${ }^{56}$ Todas las páginas web citadas han sido verificadas por última vez el día 15 de noviembre de 2020. 